\title{
Participación de Chile en el Consejo de Defensa Suramericano: moderación y pragmatismo ${ }^{1}$
}

\author{
Chile 's participation in the South American Defense Council: \\ moderation and pragmatism ${ }^{2}$
}

\author{
Jorge Riquelme Rivera ${ }^{3}$
}

Resumen: El artículo analiza la participación de Chile en el Consejo de Defensa Suramericano (CDS), desde su establecimiento en diciembre de 2008. En tal sentido, se sostiene que la contribución en dicho consejo forma parte importante de la prioridad latinoamericana declarada por la política exterior chilena. Asimismo, se argumenta que, al igual que en su participación en otras instancias de integración regional, el país ha asumido con moderación y pragmatismo sus actividades en dicho consejo. Ello ha supuesto que, junto con participar activamente en el CDS, Chile continúe fuertemente comprometido con el esquema hemisférico de seguridad y defensa.

Palabras Claves: Política Exterior de Chile, Política de Defensa, Consejo de Defensa Suramericano

Abstract: The article analyses Chile's participation in the South American Defense Council (CDS), since its establishment in December, 2008. To such effect, it asserts that its role in said Council represents an important part of the Latin American priority defined in Chilean foreign policy. Moreover, the work argues that, much in the same way as in the participation in other regional integration mechanisms, the country has carried out its activities in the Council with moderation and pragmatism. This suggests that, in addition to its active involvement in the CDS, Chile continues to be strongly committed to the hemispheric framework of security and defense.

Key Words: Chilean Foreign Policy, Defense Policy, South American Defense Council

\footnotetext{
${ }^{1}$ Recibido: 27/07/2017. Aceptado: 02/03/2018

${ }^{2}$ Este artículo forma parte de una investigación más amplia, enmarcada en la tesis "Comunidades de Seguridad Regional: una perspectiva desde América del Sur", que está siendo elaborada por el autor para el programa de Doctorado en Relaciones Internacionales de la Universidad Nacional de La Plata.

3 Magister en Estudios Internacionales, Universidad de Chile, y en Ciencias Militares (Academia de Guerra del Ejército de Chile). Doctorando en Relaciones Internacionales, Universidad Nacional de La Plata. Graduado del Centro de Estudios Hemisféricos de Defensa, Washington D.C. y de la Academia Nacional de Estudios Estratégicos (ANEPE, Chile).
} 


\section{Introducción}

Según señala el académico y ex Subsecretario de Relaciones Exteriores de Chile, Alberto Van Klaveren, la política exterior "es una política pública, pero es más que eso. Por medio de la política exterior, los Estados se relacionan con el sistema internacional y se adaptan a éste" (Van Klaveren, 2014, p. 96). En consecuencia, la política exterior corresponde a aquella política pública que guía la conducta de un Estado en el sistema internacional, con el objeto de apoyar su posicionamiento en el mismo, considerando sus particulares intereses y objetivos nacionales, así como los medios, recursos y estrategias para alcanzarlos.

Bajo esta premisa, es posible observar que desde los inicios de la década de los noventa, la política exterior de Chile asumió la tarea de reinsertar al país en las corrientes globales, luego del aislamiento vivido durante los años del régimen militar. Según señala Luis Maira, durante 16 años, más de 95 países condenaron a Chile en la Asamblea General de Naciones Unidas, por los atentados contra los derechos humanos. A ello se sumó el rompimiento o congelamiento de relaciones diplomáticas con muchos Estados, como fue el caso de México, Argelia, Italia, Francia y España (Maira, 2007, p. 164).

Ante este complejo contexto, junto con el regreso de la democracia, el nuevo gobierno debió abocarse a la tarea de la reinserción en la comunidad internacional. En la práctica, al poco tiempo de asumir el Presidente Patricio Aylwin, se retomaron las relaciones con aquellos países con los cuales habían sido suspendidas y se regularizó la participación chilena en diversas instituciones multilaterales, presentándose al país como un ejemplo de recuperación democrática. Este proceso se enmarcó en los profundos cambios que vivía el mundo, relacionados con la caída del Muro de Berlín, el fin de la Guerra Fría y el consecuente dinamismo que adquirió el proceso de globalización.

En suma, en esos años Chile enfrentaba un profundo contexto de transición interna e internacional. El país pasaba de tener una política exterior reactiva y defensiva durante el régimen militar, a una política que apuntaba a una inserción global activa e integral, sustentada en su régimen democrático, la promoción de los derechos humanos y la apertura comercial. Esta última había sido delineada, en sus elementos básicos, por el régimen anterior.

El proceso de reinserción internacional de Chile puso entre sus prioridades a la región de América Latina. Aunque esta vez la mirada sobre la integración regional fue más pragmática y menos voluntarista que en los sesenta, años en los cuales el país se configuró como uno de los principales promotores del Pacto Andino. En los noventa la prioridad latinoamericana estaba marcada por un fuerte tinte liberalizador y aperturista, que se plasmó en la plena asunción del principio del regionalismo abierto, propugnado desde la Comisión Económica para América Latina y el Caribe (CEPAL), lo que iba de la mano de la trascendencia del comercio exterior para el modelo de desarrollo chileno. El regionalismo abierto asumido en el campo de la política exterior suponía afianzar las relaciones con América Latina, pero ello no era óbice para incrementar igualmente las relaciones con otras regiones de alta relevancia, como América del Norte, Asia Pacífico y Europa.

Considerando la prioridad regional asumida por la política exterior chilena, en el presente artículo se otorga una visión general sobre la participación de Chile, desde sus orígenes, en el Consejo de Defensa Suramericano (CDS). Hasta ahora la literatura se ha concentrado en el papel de Brasil en dicho esquema regional, en el marco de su posicio- 
namiento internacional como potencia emergente (Amorim, 2012; Gratius, 2008; Merke, 2012; Saint-Pierre, 2012); así como en temáticas vinculadas con el desarrollo de la industria de la defensa en la región (Giacalone, 2014; Saint-Pierre y Zague, 2014) y la formación de una eventual identidad colectiva sudamericana (Vitelli, 2013). El rol de Chile en el CDS virtualmente no ha sido analizado en anteriores investigaciones. Intentando asumir este vacío bibliográfico, el trabajo primero analiza las tendencias que ha seguido el país respecto de la integración regional. Posteriormente, considerando la opción de la política exterior chilena por asumir, bajo un enfoque pragmático, una prioridad hacia la región, se analiza el rol del país en la constitución del CDS; para luego enfocarse en las características y prioridades que ha tenido la participación de Chile en el mencionado organismo regional hasta la actualidad.

Como se verá más adelante, con su participación en el mecanismo, junto con poner en práctica la prioridad regional declarada por su política exterior, Chile ha buscado contribuir a la estabilidad regional y a la consolidación de una comunidad pluralista de seguridad en América del Sur, entendida como un espacio regional determinado por el establecimiento de instituciones y prácticas formales de relacionamiento, que favorece el cambio pacífico y la práctica de relaciones estables y predecibles entre los actores, los que al mismo tiempo que mantienen su independencia legal, abandonan la guerra como mecanismo para la solución de las controversias que pudieren suscitarse entre ellos (Deutsch, 1974, p. 231).

Bajo este enfoque, la participación chilena en el CDS, utilizando los conceptos aportados por Joseph Nye, asumiría que el instrumento militar no sólo puede ser apreciado bajo el prisma del poder duro de la fuerza física y la coerción, sino también desde sus aportes al poder blando, como parte de una agenda de seguridad benigna y asociativa, definida por la cooperación entre los Estados, sus agencias y los diversos actores no estatales (véase Nye, 2011, p. 25). En el fondo, a través de su participación en dicho instrumento regional, el país estaría favoreciendo su inserción global, por cuanto actuando conjuntamente con los países miembros, incidiría de mejor manera en los procesos de toma de decisiones internacionales.

\section{Una mirada pragmática hacia la integración regional}

Según consigna el libro Perspectivas, Proyecciones y Desafíos de la Política Exterior de Chile, del Ministerio de Relaciones Exteriores, entre los intereses prioritarios de la política exterior está el "contribuir al fortalecimiento de la integración regional" (Ministerio de Relaciones Exteriores, 2010, p.21). En el mismo sentido, el ex Canciller Mariano Fernández ha sostenido que "La Política Exterior de Chile tiene como centro de gravedad la promoción de una identidad común en América Latina, región en la cual compartimos una historia, culturas, intereses y objetivos" (Fernández, 2010, p.48). Bajo un punto de vista pragmático, cabe señalar también que el apoyo chileno hacia la integración regional ha ido de la mano de la idea de plantear a Chile como un puente entre las economías asiáticas situadas en la cuenca del Pacífico y las economías sudamericanas (Furche, 2010, p. 20).

Bajo los supuestos del regionalismo abierto, Chile se asociaría al Mercado Común del Sur (MERCOSUR) en la reunión de Jefes de Estado y Gobierno, celebrada en San Luis en 1995. Asimismo, es miembro asociado de la Comunidad Andina (CAN) desde el año 2006, habiendo sido uno de los principales impulsores del Pacto Andino, establecido en 
1969. La calidad sólo de miembro asociado a estas iniciativas (no como miembro pleno), se debe fundamentalmente a la diferencia de las estructuras arancelarias entre Chile y tales bloques. Como señala Luis Maira, la entrada plena de Chile al MERCOSUR y la CAN obligaría a dos situaciones que no parecen viables: "que los restantes países sudamericanos rebajaran sus aranceles o que Chile los subiera para alcanzar un punto de nivelación, dadas las exigencias de un Arancel Externo Común" (Maira, 2007, p. 176).

Una concepción moderada y pragmática sobre la integración regional es la que trasunta el siguiente argumento de Mariano Fernández:

La Política Exterior de Chile tiene como centro de gravedad la promoción de una identidad común en América Latina, región con la cual compartimos una historia, cultura, intereses y objetivos. Adicionalmente, impulsamos la mayor integración posible y, parafraseando a un ex Presidente de Chile, lo hacemos en la medida de lo posible. (Fernández, 2010, p 48).

Esta posición ante la integración regional responde al interés por incrementar la estatura estratégica del país, así como su autonomía e influencia en el multilateralismo internacional, ${ }^{4}$ sin perjudicar sus intereses nacionales en virtud de ciertos voluntarismos, apreciados como propios de los años sesenta. No obstante, es justo señalar igualmente que la moderación y pragmatismo exhibido por Chile en sus relaciones con la región, en el marco del regionalismo abierto, le han valido una serie de críticas desde diversos sectores políticos y académicos -tanto a nivel nacional como internacional-, que cuestionan el verdadero compromiso chileno hacia la integración, señalando que el país habría optado por priorizar acuerdos comerciales con actores extrarregionales, antes que fortalecer sus relaciones con los países del entorno.

En el fondo, como un país con pocos recursos de poder en su sentido más tradicional y con un pequeño tamaño relativo, la participación de Chile en instancias de integración regional se aprecia como una manera pragmática de incrementar su peso y capacidad de incidencia en las decisiones mundiales, procurando resguardar sus intereses nacionales, muchos de ellos relacionados con el mantenimiento de la autonomía en materia comercial. Según señala el ex Canciller Mariano Fernández, "Sólo integrados entre nosotros, y con una visión común, podremos tener una voz fuerte como región en los problemas globales" (Fernández, 2010, p. 52). Este es también el tenor bajo el cual debe entenderse la participación chilena en el CDS.

El acercamiento a la región, en el marco de la plural inserción internacional de Chile, responde a que las exportaciones de mayor valor agregado del país se dirigen justamente a países latinoamericanos. De hecho, como señaló el Canciller Muñoz en la columna "América Latina: una prioridad", aparecida en el diario La Tercera:

...los bienes industriales exportados por Chile a la región llegaron a casi US\$29 millones el año pasado, un 7\% más que en 2013. El Mercosur es

\footnotetext{
${ }^{4}$ A este respecto, entiéndase el concepto autonomía tal cual la conciben Tokatlián y Russell, es decir, como una autonomía relacional. Tal concepto involucra una participación activa y comprometida de los países en la elaboración de las normas de la gobernanza global. Por lo tanto, ella no supone la autosuficiencia o el aislamiento de los procesos globales sino, más bien, se relaciona con el "poder para participar e influir eficazmente en los asuntos mundiales, sobre todo en organizaciones y regímenes internacionales de todo tipo" (Tokatlián y Russell, 2003: 179).
} 
el cuarto socio comercial del país, concentra el $49 \%$ de las inversiones en el exterior y el $7,6 \%$ de las exportaciones, que se elevaron a alrededor de US\$5.700 millones en $2014 .^{5}$

Últimamente, el segundo gobierno de la Presidenta Michelle Bachelet ha planteado, en materia de integración regional, la idea de la Convergencia en la Diversidad, considerando la proliferación de iniciativas que se aprecian en la región, poniendo un especial énfasis en la necesidad de avanzar en el acercamiento y coherencia entre la Alianza del Pacífico y el MERCOSUR. En los inicios de esta administración, el Ministro Muñoz, a través de la columna "Convergencia en la diversidad: la nueva política latinoamericana de Chile", aparecida en el diario El País de España, planteó que:

Chile valora la Alianza del Pacífico como esquema de integración económica y plataforma comercial de proyección colectiva a la región de Asia Pacífico; pero no compartirá pretensión alguna de concebir dicha Alianza como un bloque ideológico excluyente o antagónico con otros proyectos de integración...Convergencia en la diversidad es la política que Chile buscará promover en América Latina. Es una opción que combina realismo y voluntad política de avanzar hacia una región más integrada y autónoma. ${ }^{6}$

Este intento va de la mano de un fuerte acercamiento hacia Brasil. Para Chile, el coloso sudamericano representa un aliado estratégico en la región, cuyo liderazgo resulta esencial para apuntalar la integración. Esta idea fue claramente expresada por el Subsecretario de Relaciones Exteriores de Chile, Edgardo Riveros, durante el Coloquio ChileBrasil, celebrado el 26 de agosto de 2014 en São Paulo. En la apertura del evento, Riveros planteó que "Brasil tiene que asumir un rol de liderazgo. No en vano es la gran potencia latinoamericana. No en vano participa de los BRICS y el G-20. Por eso esperamos que desempeñe un liderazgo gravitante en la región". ${ }^{7}$

Finalmente, es necesario señalar que, en el plano de la prioridad regional declarada por la política exterior de Chile, la participación en la UNASUR se encuentra en un lugar preeminente, atendida su relevancia como instancia eminentemente política que favorece la gobernanza regional y la inserción internacional de América del Sur en su conjunto, sin impugnar los lineamientos chilenos en materia de autonomía comercial. En el último programa de gobierno de la Presidenta Michelle Bachelet, se plantea lo siguiente:

La política exterior de Chile en el próximo gobierno debe contribuir a lograr una mayor unidad regional. Debemos fortalecer nuestra participación en los distintos mecanismos de integración actualmente existentes en América Latina y, en especial en América del Sur, así como constituir a este bloque de países como una región...UNASUR debe constituirse en

\footnotetext{
${ }^{5}$ La columna se encuentra disponible en http://www.latercera.com/noticia/opinion/ideas-ydebates/2015/08/895-643517-9-america-latina-una-prioridad.shtml Recuperado en enero de 2016.

${ }^{6}$ Disponible en http://elpais.com/elpais/2014/03/12/opinion/1394642773 153377.html Recuperado en diciembre de 2015.

${ }^{7}$ Véase el Comunicado de Prensa disponible en http://www.minrel.gob.cl/subsecretario-edgardo-riverossubrayo-necesidad-de-liderazgo-brasilenoen-fortalecimiento-de-integracion-regional-en-coloquio-chilebrasil-en-sao-paulo/minrel/2014-08-26/180202.html Recuperado en septiembre de 2015.
} 
un punto de confluencia de las iniciativas de integración de América del Sur...(Bachelet, 2013, p.154).

La mirada moderada, abierta y pragmática de Chile sobre la integración, que la aprecia como una estrategia activa de inserción en las corrientes globales, como se verá en los siguientes acápites, es la que guía consecuentemente la participación del país en el CDS.

\section{El apoyo de Chile a la constitución del Consejo de Defensa Suramericano}

La interdependencia global en los campos político, económico y social en que se vio envuelto Chile desde los noventa, junto al proceso de transición democrática que se desarrollaba, tuvo diversos efectos en la vida nacional. En el ámbito de la defensa, se configuró como una oportunidad para repensar el rol de los militares en el marco del régimen democrático. Es decir, luego de la participación directa de las fuerzas armadas en la conducción política, el paulatino restablecimiento de la democracia implicó el desafío de limitar la influencia de este sector en temas relativos a la contingencia política, así como reestructurar y redefinir sus funciones (Álvarez, 2004).

En el campo de las relaciones civiles-militares, durante la primera presidencia de Michelle Bachelet, con la elaboración del Libro de la Defensa Nacional de 2010, puede ya plantearse una etapa de normalidad institucional, que se expresa, entre otros aspectos, en una positiva percepción de los militares por la ciudadanía. Según un estudio de FLACSO (2010, p.43), Chile se encuentra entre los países en los que se observa una mayor confianza hacia las fuerzas armadas. En el país, tres de cada cinco entrevistados dice confiar en las fuerzas armadas (60\%), lo que refuerza la idea de la relevancia de las buenas relaciones civiles-militares para la calidad de la democracia. Sin duda, a ello ha contribuido especialmente la positiva valoración de la ciudadanía respecto de las actividades que han realizado los militares durante los diversos eventos de desastres naturales que han azotado el país.

Según señala Rodrigo Atria, en una democracia consolidada las relaciones civilesmilitares se enmarcan dentro de las siguientes reglas: una cadena de mando claramente definida desde la autoridad civil a las fuerzas armadas; el cumplimiento de la decisión del empleo de la fuerza en manos civiles; y la activa ejecución del papel reservado al liderazgo civil en la función defensa del Estado, para que las reglas anteriores no se reduzcan a la mera posesión de una autoridad formal (Atria, 2009, p. 15).

Actualmente, puede sostenerse que, pese a los obstáculos y fricciones (Fuentes, 2002), Chile ha ingresado a una fase de consolidación democrática, es decir, aquella en la cual existe una supremacía civil y donde los militares pierden la prerrogativa de vetar la acción de los gobernantes democráticamente electos, lo que supone que ningún área de gobierno puede ser excluida del control político (Bruneau: 2005, p.120). El hecho trascendental en tal sentido, fue la promulgación en febrero de 2010 de la Ley Orgánica del Ministerio de Defensa Nacional de Chile $N^{\circ} 20.424$, que viene a consolidar la conducción política de la defensa. A este respecto, el ex Ministro de Defensa chileno, Jorge Burgos, plantea que el país "posee una estructura jurídica política con un claro control civil sobre las fuerzas armadas", donde ha cumplido un importante papel la mencionada Ley $\mathrm{N}^{\circ}$ 20.424, que establece una nueva estructura de la mencionada Secretaría de Estado, que cuenta con una Subsecretaría de Defensa, que opera como órgano asesor de primer nivel 
para el Ministro; una Subsecretaría para las Fuerzas Armadas; y un Estado Mayor Conjunto, con un papel relevante en tiempos de paz, pero con mayores atribuciones en tiempos de excepción (Burgos, 2014, p 165).

Tales avances suponen un cambio trascendental en los postulados de la antigua doctrina de seguridad nacional, impulsada luego de la Segunda Guerra Mundial desde Estados Unidos, la que suponía que los Estados latinoamericanos debían enfrentar la amenaza del comunismo, en el contexto de una "tercera guerra mundial", que se enfrentaba en el ámbito interno de los países occidentales. Bajo este enfoque, era necesario asumir un tipo de estrategia que permitiera enfrentar al "enemigo interno", conformado por aquellos partidos y fuerzas hostiles a Estados Unidos. Ello serviría de base para el impulso a la participación de los militares en la conducción política de los países latinoamericanos durante la segunda mitad del siglo XX (Maira, 2007). Como señala Margaret Crahan, esta doctrina se sustentaba en una concepción geopolítica decimonónica, que entendía a los Estados como organismos biológicos en una continua lucha por expandir su espacio vital, cuya última expresión era la guerra. A ello se unía un fuerte antimarxismo; un pensamiento católico conservador, heredero del pensamiento integrista, que a su vez derivaba de los movimientos Opus Dei y Acción Francesa; y un desencanto hacia la democracia y los partidos políticos (Crahan, 1982).

Bajo estos preceptos, se percibía a los países vecinos como potenciales amenazas a la seguridad, lo que en Chile se materializaría en situaciones extremas de tensión con Perú y Argentina. Con este último país se estuvo al borde del enfrentamiento bélico en 1978. Sin embargo, estos anacrónicos supuestos sobre la seguridad nacional y la disuasión dieron paso a nociones más modernas, que han permitido adecuar paulatinamente la política de defensa, que ha avanzado de manera firme en sus aspectos cooperativos, con una política exterior de corte fuertemente internacionalista. Muestra de ello es el importante trabajo que está realizando el Ministerio de Defensa de Chile para implementar en las fuerzas armadas un sistema de planificación por capacidades, superando el antiguo enfoque centrado en las amenazas.

De tal manera, los avances señalados en materia de control civil en el sector defensa, permiten aseverar que los postulados sobre la seguridad nacional antes enunciados, propios del contexto de la Guerra Fría, han perdido vigencia en el país. En Chile, es posible sostener que, en el ámbito de la defensa, se ha avanzado de manera paulatina pero creciente en la denominada "gobernabilidad democrática de la defensa", aunque aún quedan temas pendientes, por ejemplo, en materia de financiamiento de las fuerzas armadas y justicia militar (Flisfisch y Robledo, 2012). Del mismo modo, se ha comenzado a valorar la dimensión internacional de la defensa, como soporte fundamental de la política exterior.

En este orden de ideas, cabe señalar que el Ministerio de Relaciones Exteriores ha cumplido, con el apoyo del Ministerio de Defensa, un relevante rol para coordinar la participación del país en variadas instancias multilaterales relacionadas con las materias de paz y seguridad internacionales. En la práctica, por ejemplo, Chile ha estado fuertemente comprometido con las operaciones de paz de Naciones Unidas, estando actualmente las discusiones enfocadas en la manera en que Chile incrementará su participación en operaciones en el continente africano, lo que implica, desde luego, un relevante desafío para las fuerzas armadas en materia de preparación, despliegue, transporte estratégico y sostenimiento, entre otros. 
Además, cabe señalar que el país ha sido pionero en su apoyo al concepto de la seguridad humana, formando parte de la Red de Seguridad Humana, así como respecto de la conceptualización sobre la Responsabilidad de Proteger (Riquelme, 2014), siendo igualmente un diligente participante en los distintos foros y mecanismos multilaterales sobre asuntos humanitarios, desarme y no proliferación, entre otros. Por último, cabe señalar que el prestigio internacional de Chile en tales materias, desde la década de los noventa, lo ha llevado a ser parte en tres ocasiones del Consejo de Seguridad de Naciones Unidas, en los períodos 1995-1996, 2003-2004 y 2014-2015. En los foros relacionados con la esfera político-estratégica a nivel hemisférico y regional, Chile ha sido activo en instancias como la Comisión de Seguridad Hemisférica de la Organización de Estados Americanos (OEA), la Junta Interamericana de defensa (JID), las Conferencias de Ministros de Defensa de las Américas (CMDA) y, desde luego, el CDS, entre otros.

Respecto del CDS en particular, cabe sostener que la participación nacional en este foro ha representado una sección de relevancia de la declarada prioridad latinoamericana de la política exterior chilena. La participación de Chile en el consejo es la manifestación del trabajo mancomunado entre la Cancillería y el Ministerio de Defensa Nacional en torno a un tema de alta trascendencia para la actuación exterior de Chile, como es la prioridad regional, con el objetivo final de incrementar la estatura estratégica, la autonomía y la proyección internacional del país. La actividad en el Consejo se ha constituido en una oportunidad para estrechar lazos y aumentar la coherencia entre ambas Secretarías de Estado, lo que resulta particularmente relevante, considerando las diversas apreciaciones sobre el sistema internacional y culturas institucionales que ambas instituciones poseen.

Además, con su actuación en el consejo, el país ha buscado implementar la prioridad regional declarada por la política exterior, a la que se ha acoplado la política de defensa, tomando en cuenta las críticas sobre el eventual poco compromiso chileno con los procesos de integración vigentes. De este modo, la participación de Chile en el CDS demuestra una marcada preferencia del país por encauzar su actuación regional por los canales políticos, manteniendo al mismo tiempo su independencia en materia de negociaciones comerciales. Como expresión de lo anterior, durante la Primera Reunión de Ministros de Defensa del CDS, el entonces Ministro de Defensa Nacional de Chile, José Goñi, señaló lo siguiente en el discurso inaugural:

Nuestra identidad, como la de nuestros vecinos-vuestros países-, nos enraíza en nuestra condición sudamericana... Esencialmente, eso significa que hacemos política de Estado en los diferentes ámbitos del quehacer internacional desde este rincón de Sudamérica, teniendo siempre como referencia no solo el presente de nuestra región, sino también su destino...estamos materializando un proyecto particularmente significativo para la integración regional, en la que nos hemos comprometido con nuestros pueblos y nuestra historia en común (Ministerio de Defensa Nacional de Chile, 2009, p.97-99).

Sin descuidar la vocación global del país, las labores en dicho esquema sudamericano dan cuenta del propósito chileno de inserción a nivel internacional, tanto en lo político como en lo comercial, bajo una perspectiva regional, tal cual lo demuestra la siguiente aseveración, que aparece en un documento preparado por la Cancillería de Chile: 
Aunque la Política Exterior en materia de Seguridad Internacional tiene vocación y despliegue globales, ella debe promover y respaldar vigorosamente los instrumentos, mecanismos y foros regionales y subregionales de seguridad: el aporte de Chile a la Paz y la Seguridad Internacional se hace desde nuestra región... Chile debe mantener su compromiso con el Consejo de Defensa Suramericano de UNASUR, fortaleciendo su actividad como un mecanismo promotor de diálogo, transparencia e información entre los países de la región" (Ministerio de Relaciones Exteriores de Chile, 2018, p.63).

En un contexto internacional marcado por el fin de la Guerra Fría y la consecuente realineación del poder global -donde se aprecian evidentes tendencias hacia la integración regional y la generación de bloques-, bajo el prisma chileno, el CDS es síntoma de un progresivo proceso de convergencia en América del Sur, donde se ha planteado una progresiva pérdida de vigencia de las tradicionales nociones sobre la seguridad nacional, restándole fuerza a las clásicas hipótesis de conflicto, que percibían como potenciales enemigos a los países vecinos. Ello ha implicado comenzar a asumir la cooperación como un elemento de preeminencia en la defensa de los países. En una entrevista realizada al Director de Seguridad Internacional y Humana de la Cancillería chilena, Ministro Consejero Julio Bravo, este señalaba en tal sentido que:

UNASUR es un ámbito de acción prioritario para nuestro país. Y en esta instancia el CDS representa un mecanismo importante de seguridad cooperativa, que aúna las distintas visiones que existen en la región en temas de defensa. El CDS expresa la idea de la convergencia en la diversidad. $^{8}$

El proceso de convergencia y cooperación ha sido particularmente visible en las relaciones entre Chile y Argentina. Distinta es la situación de los países vecinos del norte, donde aún perviven ciertas desconfianzas, pero también es cierto que las diferencias se han canalizado por mecanismos jurídicos antes que a través del uso o amenaza del uso de la fuerza. Últimamente, los mayores avances en materia de cooperación bilateral se han dado en las relaciones con Perú, lo que ha sido particularmente evidente a partir de la llegada al poder del Presidente Pedro Pablo Kuczynski, retomándose una serie de mecanismos de diálogo, como es el caso de la reunión 2+2, que se reúne a nivel de Ministros de Relaciones Exteriores y Defensa, cuya última sesión se celebró en junio de 2017.

En el marco del replanteamiento de las clásicas hipótesis de conflicto, la vinculación entre la política exterior y la política de defensa ha sido fundamental para su mutua potenciación, pues las actividades que desarrollan las fuerzas armadas en materia de contribución a la paz y seguridad internacionales tienen directa relación con los objetivos nacionales y las prioridades que asigna la política exterior en torno a la inserción internacional de Chile, con una perspectiva preferente hacia la región de América Latina. Sobre la base de estos renovados enfoques en materia de política exterior y de defensa, de la mano de Brasil, Chile fue uno de los principales impulsores del CDS. En este orden de ideas, el ex Ministro Burgos ha señalado que:

\footnotetext{
${ }^{8}$ Entrevista personal concedida el 19 de octubre de 2015.
} 
...nosotros intentamos contribuir a una paz regional dentro de nuestro radio de acción, principalmente Suramérica y, en lo particular, junto con nuestros vecinos y países más cercanos, con quienes apuntamos a construir una relación distinta a que hemos sostenido durante años...Chile ha participado en la UNASUR desde su misma fundación y la Dra. Bachelet fue también la primera presidenta pro témpore de la organización. Y, desde un principio, nosotros nos hemos comprometido firmemente con la consolidación de Suramérica como una zona de paz, realizando un gran esfuerzo en ese sentido (Burgos, 2014, p. 174).

Chile ejerció la Presidencia Pro Témpore de la UNASUR entre el 23 de mayo de 2008 y el 10 de agosto de 2009. Durante su gestión, el país procuró que la organización avanzara en su consolidación, promoviendo la aprobación de su Tratado Constitutivo e impulsando el establecimiento de diversos consejos sectoriales y grupos de trabajo (Flisfisch, 2010, p. 60). Entre tales Consejos es el CDS el que posee un mayor perfil político y el que más logros ha demostrado.

Durante la Presidencia chilena, y una vez conocida la decisión de los mandatarios de los países de la UNASUR respecto de crear un Grupo de Trabajo para definir los términos de funcionamiento de un Consejo de Defensa a nivel sudamericano, el Gobierno de Chile se planteó la tarea de organizar el trabajo. La creación del CDS bajo la Presidencia chilena, como una instancia de consulta y coordinación en el ámbito de la defensa, representó un hito en materia de cooperación regional. Para este fin se estableció una Presidencia Pro Témpore del Grupo de Trabajo, que recayó en Gonzalo García Pino, entonces Subsecretario de Guerra del Ministerio de Defensa Nacional. De este modo, surgió un equipo de trabajo interinstitucional, compuesto por funcionarios de la Subsecretaría de Guerra y del gabinete del Ministro de Defensa, así como del Ministerio de Relaciones Exteriores -particularmente de las Direcciones de Planificación, Seguridad Internacional y Protocolo (Ministerio de Defensa Nacional, 2009, p. 67)

Según señalaba en 2009, el entonces Ministro de Defensa Nacional de Chile, Francisco Vidal:

... la creación del Consejo de Defensa es un hito transcendental, pues satisface un antiguo anhelo regional por contar con un espacio de encuentro que proyecte una perspectiva común y orientada hacia el futuro sobre nuestros desafíos en materia de Defensa...Estos propósitos comunes, impensables hace algunos años, son posibles hoy gracias a la trayectoria de democratización de nuestras naciones, donde los grandes lineamientos de la Defensa emanan de la autoridad investida por los ciudadanos, la política de Defensa se entiende como una política de Estado y el poder civil convive en armonía con las Fuerzas Armadas (Ministerio de Defensa Nacional de Chile, 2009 p. 15-16).

En la misma línea, Gonzalo García sostuvo que:

Efectivamente la dinámica política internacional en el siglo XXI exige estar en lo nacional y en lo cosmopolita como parte de un mismo desafío. Y en esa perspectiva la defensa en la región será un asunto que, más allá de su formato institucional, siempre requerirá de un ejercicio consciente de diálogo y cooperación. Por lo demás, este desafío se inscribe en uno 
mucho mayor, cual es la descripción de una nueva etapa mundial con puntos de inflexión de la larga historia y que nos enfrenta a un ciclo de un "auge del resto", que lidera China, India y con perspectivas sugerentes de Brasil o Rusia..." (Ministerio de Defensa Nacional de Chile, 2009, p.32).

Desde Chile, la constitución del CDS se inscribe en un esfuerzo mayor, que pretende contribuir a la inserción internacional de América del Sur en el contexto cada vez más multipolar que se aprecia en el mundo. Ello va de la mano de un sostenido apoyo del país al multilateralismo, el cual pasa a constituirse como un complejo mecanismo de relacionamiento internacional, que promueve reglas claras y disciplinas transparentes, permitiendo, en consecuencia, otorgar oportunidades de participación a todos los actores.

De este modo, desde la perspectiva de Chile, sólo actuando de manera coordinada, la región puede tener una mayor incidencia en los procesos internacionales de toma de decisiones en materia de paz y seguridad, aportando con su propia visión desde el mundo del Sur. El rol que pueda jugar Sudamérica resulta especialmente relevante, considerando su situación como una de las zonas más pacíficas del mundo, desde el punto de vista del conflicto interestatal, libre de armas de destrucción masiva y con el menor gasto en armamentos, a lo que se agrega el predominio, si bien con importantes desafíos, de regímenes de gobiernos democráticos -donde los militares están sujetos a las autoridades civiles-, y donde gran parte de los países participan de manera destacada en operaciones de paz. En suma, la paz podría representar una suerte de "exportación no tradicional" de la región en las áreas más conflictivas del mundo.

Considerando este último punto, cabe anotar que el proceso de convergencia que se aprecia en América del Sur en materia de defensa, cuya expresión última es el desarrollo que evidencia el CDS, vivió un punto de inflexión con la participación de países de la región en la MINUSTAH, que se convirtió en un escenario privilegiado para el entrenamiento de las fuerzas armadas pero, sobre todo, para el trabajo conjunto y la generación de confianzas entre los militares participantes de dicha misión de paz. Como señala Gonzalo García:"...hay un antes y un después desde la operación de paz de MINUSTAH en Haití. Cooperamos en Haití convirtiendo ese escenario en pieza maestra del cambio de las percepciones de defensa más amplio y profundo que ha tenido la región en décadas..." (Ministerio de Defensa Nacional de Chile, 2009, p.35).

Junto con lo antes reseñado, se debe plantear que Chile, al momento en que se analizaban las características que tendría el nuevo organismo regional, planteó, y así lo ha seguido haciendo, que éste se constituyera como un foro exclusivamente defensivo, sin abarcar otras áreas de seguridad, en su sentido amplio. O sea, que correspondía a un Consejo de Defensa y no a un Consejo sobre temas de seguridad. De hecho las materias relacionadas con la seguridad pública son tratadas en otro Consejo sectorial de la UNASUR, cual es el Consejo Suramericano en materia de Seguridad Ciudadana, Justicia y Coordinación de Acciones contra la Delincuencia Organizada Transnacional, creado en noviembre de 2012 en Lima.

Asimismo, Chile ha promovido que el CDS se mantenga como un foro flexible de diálogo estratégico, que canalice las iniciativas de cooperación bilateral y multilateral que se dan en la región en temas de defensa, sin pretender, hasta el momento, avanzar hacia la constitución de una alianza militar en contra de algún país en particular, como Estados Unidos. Esta idea queda clara en la siguiente aseveración de Gonzalo García: “EI CDS se 
inscribe dentro de los mecanismos propios de la seguridad cooperativa. Por lo tanto, se aparta de la dimensión operativa que podría sugerir una alianza de naturaleza militar abarcadora de una política regional propiamente tal" (Ministerio de Defensa Nacional de Chile, 2009, p. 38).

Para Chile, el CDS debe mantenerse como una instancia de seguridad cooperativa, es decir, como un mecanismo liviano desde el punto de vista institucional, que favorezca el diálogo, la estabilidad y la cooperación en defensa entre sus miembros. Como señala Martha Bárcena al respecto, el propósito de la seguridad cooperativa es prevenir la guerra, evitando que se conjunten los medios necesarios para una agresión, en tanto: "Su principio clave sería lograr el 'compromiso cooperativo' de todos los Estados para regular el tamaño, la integración técnica, los flujos de inversión y las prácticas operativas de las fuerzas militares de los países, por mutuo consentimiento y para beneficio de todos" (Bárcena, 2000, p.18).

Ciertamente, otros países han seguido un camino distinto en el marco del CDS, como es el caso de Venezuela, que en numerosas ocasiones ha postulado la idea de avanzar en la creación de una OTAN sudamericana (OTAS). Ya el año 2006 el Presidente Hugo Chávez, antes del establecimiento del CDS, había declarado ante diversos presidentes sudamericanos que "Debe llegar el día en que el Mercosur tenga una organización de defensa donde vayamos fusionando las Fuerzas Armadas de nuestros países y donde enmarquemos una estrategia propia de seguridad, soberanía y defensa". También, poco antes del establecimiento del Consejo, recordó que él había propuesto con anterioridad la creación de una OTAS, tema que retomó en diversas ocasiones en el marco del ALBA, planteando la necesidad de desarrollar un "ALBA militar", que incluyera componentes relacionados con el uso de la fuerza y la creación de una alianza militar defensiva de corte antiimperialista (Alda, 2012).

\section{Participación y prioridades de Chile en el Consejo de Defensa Suramericano}

Siendo la participación en el CDS uno de los elementos principales para dar contenido y forma a la prioridad regional declarada por la política exterior de Chile, así como a una política de defensa que paulatinamente avanza en su carácter cooperativo -por sobre las nociones geopolíticas vinculadas con la clásica concepción sobre la disuasión-, el país otorga una especial trascendencia a dicho organismo regional, en tanto se constituye como el primordial foro de diálogo político en temas de defensa en la región.

EI CDS representa una instancia valiosa de relacionamiento, donde dialogan los vecinos y paravecinos de Chile, estando presentes actores relevantes en materias de defensa, como lo son Brasil y Argentina, importantes socios chilenos en materia de política exterior y de defensa. Junto a la relevancia de las interacciones con éstos países, según señalaba en 2015 el entonces encargado del tema del CDS en el Ministerio de Defensa Nacional de Chile, señor Carlos Maldonado, también destaca el que la participación en dicho organismo regional ha permitido igualmente incrementar el diálogo y la coopera- 
ción con otros países de la región, como es el caso de Venezuela, país con el cual cabría suponer importantes divergencias en otras instancias. ${ }^{9}$

Hasta el presente, ciertos lineamientos generales han guiado el desarrollo del CDS, los cuales pueden resumirse como sigue: primero, que el organismo no pretende constituirse como una alianza militar; segundo, que es un Consejo de Defensa y no de Seguridad; tercero, que no fue establecido contra ningún país en particular; y cuarto, su gradualidad y flexibilidad, donde cumple un rol relevante el que las decisiones sean adoptadas mediante el consenso. Según Carlos Maldonado, la participación chilena está firmemente basada en tales principios, los que el país ha apoyado desde la misma creación del CDS.

Cabe señalar que la opción chilena por apoyar desde sus orígenes la constitución del CDS no involucra una determinada concepción geopolítica, inclinada a favorecer la integración de América del Sur -como sí lo es para Brasil, preocupado de México, su competidor por el liderazgo regional-, por sobre la integración de América Latina en su conjunto. Más bien, desde la perspectiva de Chile, el establecimiento y desarrollo del CDS representa una manera de sumar esfuerzos por avanzar en la integración de América Latina como un todo, dejando la puerta abierta para la eventual adhesión de nuevos miembros. Gonzalo García ha señalado lo siguiente al respecto:

...construir identidad suramericana en defensa, que tome en cuenta características subregionales y nacionales y que contribuya al fortalecimiento de la unidad de América Latina y Caribe se inscribe en la trayectoria histórica de Sudamérica. No es una identidad cerrada puesto que apela abiertamente a la condición latinoamericana referida en el Estatuto como una perspectiva de integración futura de cualquier país de América Latina y el Caribe (Ministerio de Defensa Nacional de Chile, 2009, p. 39-40).

Como se señaló anteriormente, al igual que ante los diversos procesos de integración en marcha en la región, Chile ha asumido con moderación y pragmatismo su participación en el CDS, por cuanto ésta no ha supuesto romper con los mecanismos de defensa y seguridad hemisféricos, como son las Conferencias de Ministros de Defensa de las Américas, la JID, el Colegio Interamericano de Defensa y la Comisión de Seguridad Hemisférica de la OEA. De hecho, la Presidencia de Chile en la JID durante el período 2013-2015, en la persona del General Werther Araya, es una clara señal de apoyo a este sistema interamericano. ${ }^{10}$

Esta postura de pragmatismo es comprensible, dado que, con todas sus limitaciones, el sistema hemisférico continúa aportando a la estabilidad continental y a la agenda nacional de cooperación en seguridad y defensa. Tampoco debe olvidarse que la participación chilena en tales mecanismos supone el apoyo también a los países más prominentes del continente, como son Estados Unidos y Canadá, socios relevantes para el país andino. Lo anterior, sin perjuicio de la necesidad de impulsar cambios trascendentales a

\footnotetext{
${ }^{9}$ Entrevista personal concedida el 27 de octubre de 2015.

${ }^{10}$ En el plano de la seguridad pública, también habría que anotar que Chile participa activamente de otras instancias hemisféricas, como son la Comisión Interamericana para el control del abuso de Drogas (CICAD), el Comité Interamericano Contra el Terrorismo (CICTE) y la Convención Interamericana contra la fabricación y tráfico ilícito de Armas de Fuego, Municiones, Explosivos y otros materiales relacionados (CIFTA).
} 
dicho esquema hemisférico, que expresa evidentes signos de anacronismo y obsolescencia. El Director de Seguridad Internacional y Humana de la Cancillería chilena, Julio Bravo, confirma estos argumentos, señalando que "nuestra participación en el CDS no es contra nadie, ello supone no excluir nuestras relevantes relaciones con otros países del hemisferio, como Estados Unidos. Desde Chile valoramos el sistema hemisférico". ${ }^{11}$

En la misma línea de moderación, es que Chile sostiene la idea de que el Consejo sólo abarque aquellos temas tocantes a los asuntos de defensa. Esta tendencia posiblemente se mantendrá, atendidas las heterogeneidades que se aprecian en la región respecto del modo en que los países miembros del CDS conciben o conceptualizan los aspectos relacionados con la seguridad y la defensa, lo que consecuentemente impacta en las tareas que asumen las respectivas fuerzas armadas. Es decir, las dificultades que aún se aprecian en alcanzar conceptualizaciones y metodologías comunes en estas materias, desde luego, afectarán la profundización de la integración en tal sentido.

Respecto de los temas que contempla la agenda del CDS -que se trabaja en el marco de los planes de acción anuales- y dada su experiencia política en ciertas temáticas, Chile impulsó en un principio el tratamiento de materias como la modernización de los Ministerios de Defensa y la homologación de los gastos. En la actualidad, el trabajo chileno se ha concentrado en los asuntos de género, relacionados con la implementación de la resolución 1325 del Consejo de Seguridad de Naciones Unidas sobre Mujer, Paz y Seguridad; el enfrentamiento de situaciones de desastres naturales $y$, vinculado con ello, los efectos del cambio climático; crecientemente ha demostrado también interés por la esfera de la industria de la defensa; y, por último, por el área de la formación y capacitación. ${ }^{12}$ Destaca en tal sentido el protagonismo de Chile en la creación de un Grupo de Trabajo sobre Perspectiva de Género en el CDS, que aparece en los planes de acción 2016 y 2017, en continuidad con la organización en 2015 de un seminario sobre integración de la perspectiva de género en el ámbito de la defensa (plan de acción 2015). En la misma línea, cabe subrayar la celebración, en Santiago de Chile, del primer y segundo curso sobre perspectiva de género en defensa, que figuran en los planes de acción 2016 y 2017, respectivamente.

Otro tema que cabe subrayar especialmente, es el enfrentamiento de los desastres naturales. A este respecto, en una entrevista realizada al ex Ministro de Defensa Nacional, Jorge Burgos, por parte de la revista Patria de Ecuador, este fue claro en subrayar los aportes de Chile en la formulación de los lineamientos para la protección de los recursos naturales en la región y en la elaboración del Atlas de Mapas de Riesgo de Desastres Naturales en Suramérica (Burgos, 2014). También, Chile organiza anualmente el Ejercicio UNASUR, con el objeto de promover la conformación de un sistema regional de cooperación en defensa para que, en caso de emergencias o catástrofes naturales, se generen redes de apoyo bajo un protocolo de cooperación mutua (planes de acción 2015, 2016 y 2017). Si bien estas temáticas se relacionan con los asuntos propios de la seguridad, de todos modos, no contienen la carga política y efectos asociados que sí poseen otras esferas, como lo es la utilización de los medios militares para el combate contra el narcotráfico y el crimen organizado. En Chile, el empleo de las fuerzas armadas ante situaciones de

\footnotetext{
${ }^{11}$ Entrevista personal concedida el 19 de octubre de 2015.

${ }^{12}$ En entrevista sostenida con Carlos Maldonado, del Ministerio de Defensa Nacional, el 27 de octubre de 2015.
} 
desastres naturales ha sido altamente valorado por la ciudadanía, representando una relevante oportunidad de interacción civil-militar. Estas experiencias, a lo que se agrega la exposición del país a un amplio abanico de desastres naturales -entre los que se cuentan sequías, incendios forestales, inundaciones y terremotos, muchos de los cuales han ocurrido de manera simultánea- han estado al centro de los últimos aportes de Chile a los trabajos del CDS.

Además de los tópicos antes señalados, también cabe recalcar el énfasis chileno en lo referente a la generación de una comunidad epistémica y la formación de un pensamiento estratégico regional. La relevancia que Chile ha otorgado a la promoción de estas materias explica el empeño puesto en la candidatura del académico chileno Mladen Yopo para ejercer la Subdirección del Centro de Estudios Estratégicos de Defensa del CDS (CEED). Su elección se realizó, por consenso, durante la XI Reunión de la Instancia Ejecutiva del CDS, celebrada en Montevideo entre los días 10 y 11 de diciembre de 2014. En la ocasión, el Subsecretario de Defensa de Chile, Marcos Robledo, resaltó el compromiso chileno con la UNASUR y, especialmente, con el CDS. El Subsecretario fue enfático en referirse a la importancia de la labor del CEED para afianzar un pensamiento estratégico regional, representando la candidatura de Yopo una oportunidad para seguir contribuyendo desde Chile al fortalecimiento del Centro.

En el fondo, la participación de Chile en el CDS demuestra la opción del país por favorecer un entorno estable y coherente con su modelo de desarrollo abierto al mundo, pero con una perspectiva latinoamericana. Ello se concatena con una política de defensa que crecientemente avanza en sus rasgos cooperativos, que deja de lado la idea de asumir a los vecinos como parte de las amenazas $y$, al revés, pasa a valorarlos como socios en una tarea común de desarrollo y bienestar, o sea, como parte fundamental del quehacer de favorecer, de manera cooperativa, un entorno regional seguro y estable. Esta idea forma parte fundamental del programa de gobierno 2014-2018 de la Presidenta Michelle Bachelet. En el documento, en la sección dedicada a Defensa, se plantea lo siguiente:

...la política de Defensa Nacional tendrá como objetivo principal de mediano y largo plazo, generar una Comunidad de Seguridad en América del Sur que garantice la paz y elimine definitivamente la amenaza de la guerra, siendo el Consejo de Defensa de UNASUR la institución para avanzar en esta materia. En el mismo sentido, se fomentará la cooperación y extensión de medidas de confianza mutua y de prevención de crisis con nuestros vecinos y en la región, así como también el compromiso colectivo y verificable de una política de plena transparencia de los presupuestos y las adquisiciones militares entre los países de la región" (Bachelet, 2013, p. 150).

En el ámbito doméstico, es necesario señalar que el CDS se ha constituido para Chile como una instancia relevante para apuntalar la coordinación del trabajo de los Ministerios de Relaciones Exteriores y de Defensa, con el objeto de proyectar regional e internacionalmente al país. El Director de Seguridad Internacional y Humana del Ministerio de Relaciones Exteriores de Chile, Julio Bravo, sostiene a este respecto que "la participación del país en el CDS ha representado un mecanismo valioso para ayudar a la mutua coordi- 
nación. El Ministerio de Defensa se ha acoplado a la idea de la convergencia en la diversidad. Defensa se ha transformado en un brazo de la política exterior" ${ }^{13}$

En síntesis, como es posible apreciar, de la mano de Brasil, Chile fue uno de los principales impulsores de este organismo regional. Para este país, el CDS se ha transformado en una instancia apropiada para favorecer la estabilidad de la región, apoyando la generación de confianza entre los miembros y previsibilidad en las conductas, lo que consecuentemente ha disminuido la incertidumbre y reforzado la estabilidad de las relaciones entre los miembros.

Por lo demás, en las reuniones del CDS se aprecia un elevado nivel de diálogo e interacción entre los países, no estando las conversaciones condicionadas por las fragmentaciones y alianzas que sí se aprecian en otros foros. O sea, en los encuentros del CDS es posible ver trabajar fluida y conjuntamente a delegaciones nacionales que en otras instancias tendrían fuertes divergencias.

En el fondo, para Chile, el CDS ha favorecido el desarrollo de una comunidad pluralista de seguridad a nivel sudamericano, donde los países incrementan la confianza mutua, abandonando el recurso a la guerra como medio de solución de sus diferencias, lo que es particularmente coherente con el modelo de desarrollo chileno, cuyo comercio internacional requiere como condición de un ambiente regional e internacional seguro y estable.

\section{Conclusiones}

Como se señaló en este trabajo, el CDS fue establecido en diciembre de 2008, durante la Presidencia Pro Témpore de Chile en la UNASUR, siendo actualmente el consejo sectorial que posee un mayor perfil político en dicha instancia regional. En sus orígenes, el CDS se planteó como una instancia flexible de consulta y coordinación en el ámbito de la defensa, representando un hito en materia de cooperación regional. Hasta ahora, las labores del CDS están guiadas bajo ciertos lineamientos generales, que pueden sintetizarse de la siguiente manera: primero, que el organismo no pretende constituirse como una alianza militar; segundo, que es un Consejo de Defensa y no de Seguridad; tercero, que no fue establecido contra ningún país en particular; y cuarto, su gradualidad y flexibilidad. Chile ha sido un firme defensor de tales postulados.

Bajo el prisma de la política exterior de Chile, y de manera coherente con su política de defensa, la participación nacional en el CDS representa una parte importante de la declarada prioridad hacia la región de América Latina. En el marco de este foro, dialogan los vecinos y paravecinos de Chile, estando presentes actores y socios relevantes para el país, como son Brasil y Argentina.

Sin perjuicio de lo anterior, al igual que ante otros mecanismos de integración regional, Chile ha asumido su participación con altos grados de moderación y pragmatismo. Ello ha supuesto participar activamente en el CDS, pero sin romper con los mecanismos de defensa y seguridad hemisféricos, donde se encuentran potencias de nivel internacional, como Estados Unidos y Canadá.

\footnotetext{
${ }^{13}$ Entrevista personal concedida el 19 de octubre de 2015.
} 
En último término, como un mecanismo de seguridad cooperativa, el CDS ha representado para Chile una instancia valiosa de diálogo estratégico, que ha encuadrado los intereses y objetivos defensivos de los países al consenso regional, lo que ha favorecido un ambiente de seguridad, promoviendo relaciones predecibles y pacíficas entre sus miembros. Al mismo tiempo, ha favorecido la presencia internacional de la región en un contexto internacional con importantes atributos de multipolarismo.

En tal sentido, para el país andino, el CDS ha favorecido, concatenadamente, la presencia y proyección internacional de los países que participan de éste, incrementando sus capacidades de influencia en la toma de decisiones internacionales en los ámbitos político y estratégico. En suma, como parte de un proceso de integración en marcha, el CDS, más que restar poder y soberanía a los Estados, ha incrementado sus atributos en el marco de la interdependencia global actual.

Bajo la perspectiva de Chile, la participación de los países en el consejo ha favorecido la confianza mutua en el entorno vecinal y regional, apuntalando un entramado de intereses conexos de desarrollo y paz, lo que ha permitido abandonar definitivamente el recurso a la guerra como medio de solución de los conflictos, siendo la cooperación en defensa un elemento funcional con la pretensión de favorecer una región estable y segura. Ello resulta particularmente coherente con los intereses de desarrollo de los países de la región, que requieren de un ambiente regional e internacional seguro, de manera de poder disfrutar los "dividendos de la paz".

Nuevas investigaciones podrían indagar igualmente en las tendencias institucionales de la UNASUR y el CDS, a fin de sugerir nuevos desarrollos en este ámbito. Con el objeto de contribuir a la inserción política internacional de América del Sur, un camino a seguir podría ser evaluar el establecimiento de una política de defensa a nivel regional, lo que requiere, desde luego, avanzar en lineamientos comunes en el campo de la política exterior y de seguridad, como ha sido el recorrido que ha seguido la Unión Europea. Un desempeño exitoso en este sentido debiera desembocar, en el largo plazo, también en el establecimiento y despliegue de fuerzas y misiones regionales en el exterior. Con todas sus dificultades, esta senda sería coherente con los impulsos que está dando Naciones Unidas al respecto, atendido el relevante papel que pueden cumplir los organismos regionales en materia de paz y seguridad internacionales.

Como una Zona de Paz, América del Sur puede representar un singular ejemplo y agente estabilizador ante un contexto mundial que parece caminar hacia el desfiladero, dándole muchas veces la razón a los supuestos más pesimistas del Realismo, tal cual lo demuestra el comportamiento exterior de Estados Unidos bajo la administración de Donald Trump o la siempre preocupante situación del Medio Oriente y la Península de Corea.

\section{Bibliografía}

-Alda, S. (2012). "El espacio militar en el ALBA". En Alda, S. y Gómez, V. (Eds.). El concepto y las relaciones multilaterales de seguridad y defensa en el contexto de la UNASUR. Quito: UNED-Ministerio de Defensa Nacional de Ecuador.

-Álvarez, D. (2004). "Fuerzas Armadas en Chile: entre la configuración de nuevos roles y la normalización de las relaciones cívico-militares". Buenos Aires: CLACSO. Dispo- 
nible en http://biblioteca.clacso.edu.ar/clacso/becas/20101115100812/alvarez.pdf Recuperado en septiembre de 2015.

-Amorim, C. (2012). "Estrategia de Defensa de Brasil y de América del Sur". Revista de Ciencia Política, $\mathrm{N}^{\circ} 32$.

-Atria, Rodrigo. (2009). "Chile y su defensa. Transformaciones y desafíos". Política y Estrategia, $\mathrm{N}^{\circ} 113$.

-Bachelet, M. (2013). Programa de Gobierno Michelle Bachelet 2014-2018. Disponible en http://www.minsegpres.gob.cl/wp-content/upLoads/2014/04/ProgramaMB.pdf Recuperado en septiembre de 2014.

-Bárcena, M. (2000). "La reconceptualización de la seguridad: el debate contemporáneo". Revista Mexicana de Política Exterior, № 59.

-Bruneau, T. (2005). “Civil-Military Relations in Latin America: The Hedgehog and the Fox Revisited". Revista Fuerzas Armadas y Sociedad, Año 19, № 1-2.

-Burgos, J. (2014). "La mejor forma de construir una cultura de paz es con más democracia”. Patria. Análisis Político de la Defensa, $\mathrm{N}^{\circ} 3$.

-Crahan, M. (1982). "National security ideology and human rights". En Crahan, M (ed.). Human rights and basic needs in the Americas. Washington D. C.: Georgetown University Press.

-Deutsch, K. (1974). El análisis de las relaciones internacionales. Buenos Aires: Paidós.

-Fernández, M. (2010). “América Latina: su integración, prioridad en la Política Exterior de Chile. En Ministerio de Relaciones Exteriores de Chile. El mundo desde el sur. Voces de Chile en Política Exterior. Santiago de Chile: Gobierno de Chile.

-FLACSO. (2010). Estudio de Opinión Pública en Latinoamérica 2009-2010. Gobernabilidad y Convivencia Democrática en América Latina. San José de Costa Rica: FLACSO.

-Flisfisch, A. (2010). "Las razones del compromiso de Chile con UNASUR". En Ministerio de Relaciones Exteriores de Chile. El mundo desde el Sur. Voces de Chile en política exterior. Santiago de Chile: Gobierno de Chile.

-Flisfisch, A. y Robledo, M. (2012). Gobernabilidad democrática de la defensa en Chile: un índice para el período 1990-2010. Santiago de Chile: PNUD.

-Fuentes, C. (2002). "Resisting change: security-sector reform in Chile". Journal of Conflict, Security \& Development, Año 1, №2.

-Furche, C. (2010). "Política comercial de Chile: 20 años de negociaciones y los próximos desafíos". En Ministerio de Relaciones Exteriores de Chile. El mundo desde el sur. Voces de Chile en Política Exterior. Santiago de Chile: Gobierno de Chile.

-Giacalone, R. (2014). “UNASUR y la industria de la defensa en Sudamérica”. Patria, N² 2.

-Gratius, S. (2008). ¿Hacia una OTAN sudamericana? Brasil y un Consejo de Defensa Sudamericano. Madrid: Fride.

-Maira, L. (2007). "La política exterior chilena en los años de la Concertación”. En Consani, N.; Sepúlveda, A. y; Zeraoui, Z. Transitando los inicios del siglo XXI. Las relaciones 
internacionales de Argentina, Chile y México. Buenos Aires: Grupo Editor Latinoamericano.

-Merke, F. (2012). "Brasil, política exterior y programa nuclear”. En DerGhougassian, K. (coord.), La defensa en el siglo XXI. Argentina y la seguridad regional (pp. 119153). Buenos Aires: Capital Intelectual.

-Ministerio de Defensa Nacional de Chile. (2009). Consejo de Defensa Suramericano. Crónica de su gestación. Santiago de Chile: Gobierno de Chile.

-Ministerio de Relaciones Exteriores de Chile. (2010). Perspectivas, proyecciones y desafíos de la política exterior de Chile. Santiago: Gobierno de Chile.

-Ministerio de Relaciones Exteriores de Chile. (2018). Política exterior de Chile 2030. Santiago: Gobierno de Chile.

-Nye, J. (2011). The future of power. New York: Public Affairs.

-Riquelme, J. (2014). "Nuevos horizontes del multilateralismo global: el desarrollo de la Responsabilidad de Proteger y la perspectiva de Chile". Relaciones Internacionales, $\mathrm{N}^{\circ} 46$.

-Saint-Pierre, H. (2012). "La construcción de la defensa en el Brasil contemporáneo”. En Alda, S. y Saint-Pierre, H. (Coords.). Gobernabilidad y democracia. Defensa y transiciones de Brasil y España. Santiago de Chile: RIL Editores.

-Saint-Pierre, H. y Zague, J. (2014). “La industria de la defensa y la autonomía estratégica: el caso de Brasil”. Patria, $\mathrm{N}^{\circ} 2$.

-Tokatlián, J. y Russell, R. (2003). “De la autonomía periférica a la autonomía relacional: una mirada teórica desde el Cono Sur". Perfiles Latinoamericanos, $N^{\circ} 21$.

-Van Klaveren, A. (2014). "El análisis de la política exterior: Una visión desde América Latina". En Legler, T., Santa Cruz, A. y Zamudio, L. (eds.) Introducción a las Relaciones Internacionales: América Latina y la Política Global. México: Oxford University Press.

-Vitelli, M. (2013). "Teoría y práctica de las identidades colectivas en las Relaciones Internacionales. El caso del Consejo de Defensa Sudamericano". Reflexión Política, Vol. $15, N^{\circ} 30$. 